\title{
EL ORDEN PÚBLICO EN LA VILLA DE BIAR DURANTE EL SIGLO XVIII (1750-1798)
}

\author{
Leonor MALDONADO \\ Universidad de Alicante
}

\section{Resumen}

Se estudian las causas de la violencia cotidiana en una villa alicantina de realengo durante la segunda mitad del siglo XVIII, y la actuación de la justicia local, que hasta 1791 estuvo a cargo de dos alcaldes ordinarios. El nombramiento de un Alcalde Mayor de origen foráneo consiguió reducir considerablemente los problemas de orden público.

\begin{abstract}
The causes of the daily violence in a villa of Alicante, during the second half of the 18 th Century, are studied in this article as well as the performance of the local justice which depended on two «alcaldes ordinarios» until 1791. The appointment of an «Alcalde Mayor» with foreign origins managed to reduce the public order problems considerably.
\end{abstract}

En España, el siglo XVIII fue, en lo que respecta al orden público, un período de transición entre la pervivencia de los problemas del siglo anterior y los cambios que se producirán en la época contemporánea, arrastrándose, por tanto, a lo largo de la centuria viejos conflictos propios de una sociedad de Antiguo Régimen ${ }^{2}$. Anteriores estudios han puesto de manifiesto que ésto se hizo patente en la realidad valenciana, en donde se aprecia una continuidad de los comportamientos virulentos en la primera mitad del siglo XVIII, aunque atenuados por los mayores medios a disposición de las autoridades al servicio de la nueva administración borbónica. Ésta tuvo como principal preocupación, acabar con la enraizada violencia de un pueblo de naturaleza vehemente y conflictiva, que además no había demostrado su total lealtad a la nueva dinastía ${ }^{2}$.

1. MARTÍNEZ RUIZ, E., La seguridad píblica en el Madrid de la llustración, Secretaría General Técnica del Ministerio del Interior. Madrid, 1988, pp. 13-14.

2. GIMÉNEZ LÓPEZ, E, «EI orden público en tierras valencianas durante la primera mitad del siglo XVIII» en Poder político e instituciones en la España Moderna. Instituto de Cultura «Juan Gil-Albert», Diputación de Alicante, 1992, pp. 95-112. 
Es en la violencia cotidiana donde el siglo XVIII tiene mucho de continuador de los siglos precedentes y a ella haremos referencia, tratando de descender al terreno de la vida diaria de una comunidad pues se obtienen unas dimensiones humanas que nos permiten una aproximación más directa y fiel de las relaciones entre los individuos, en este caso entre los habitantes de Biar. Era ésta una villa de realengo con un importante pasado histórico por su valor estratégico, y que en el Setecientos dependía, a efectos jurisdiccionales y administrativos, del Corregimiento de Jijona, que tuvo gobernador militar hasta 1753 en que se redujo a corregimiento de letras 3 .

La principal fuente documental en la que hemos basado el estudio la constituyen los autos judiciales abiertos por la Real Justicia de la villa, en donde quedó registrada la actividad considerada delictiva que, ya fuera en el ámbito privado o en el público, alteró de alguna manera la paz de sus moradores ${ }^{4}$.

La administración de justicia en los municipios valencianos del XVIII respondió al modelo castellano recayendo, en el caso de las sedes corregimentales, en la figura del alcalde mayor, que dependiente del corregidor, tenía como principal función actuar como juez en los pleitos y causas civiles y criminales. La naturaleza militar de la mayor parte de los corregidores valencianos, faltos de la preparación jurídica necesaria, otorgó gran importancia a los alcaldes mayores que eran licenciados en derecho y por tanto letrados sin excepción ${ }^{5}$. En los municipios de menor entidad como fue Biar, las funciones judiciales correspondieron a dos alcaldes ordinarios elegidos anualmente de entre los naturales de la villa y auxiliados en su cargo por los alguaciles encargados de detener a los culpables. Si hasta 1780, sólo en las sedes corregimentales hubo alcalde mayor de nombramiento regio, a partir de esa fecha, otros municipios que carecían de ese cargo pasaron a tenerlo, entre ellos el biarense, que fue dotado de nueva vara en 1791, cuando la conflictividad en la villa se intensific $\sigma^{6}$.

La tipología de los delitos, así como sus motivaciones fueron muy variadas, pero ante todo se aprecia una constante de las riñas y pendencias en las que se vieron envueltos vecinos de toda edad y condición social.

La chispa de la discordia podía venir dada por la acusación difamatoria. La imputación de robos de la cosecha era frecuente, tratándose casi siempre de hurtos menores: dos mujeres iniciaron una disputa por «unas alubias de bajocas», golpeándose recíprocamente con una alpargata de cáñamo y con una olla en la cabeza ${ }^{7}$. Un labrador acusó a otro de haberle «segado unas matas de paniso», tildándole de pícaro y amenazándole a pedradas y empujones ${ }^{8}$.

3. IRLES VICENTE, M.C., El régimen municipal valenciano en el siglo XVIII. Estudio institucional Institut de Cultura «Juan Gil-Albert», Generalitat Valenciana, Alicante, 1996, pag. 122

4. ARCHIVO HISTÓRICO DE BIAR, «Corrección, Seguridad y Orden Público.IV Administración de Justicia. 3, Juzgado de Paz».

5. GIMÉNEZ LÓPEZ, E., «L'Administració borbònica a València. Una administració militaritzada» en L'Epoca borbònica fins a la crisi de L'Antic Règim, Història del País Valencià. Vol. IV. Edicions 62, Barcelona, 1990, pag. 188.

6. IRLES VICENTE, M.C., «Nuevas varas valencianas a finales del Setecientos: génesis y evolución» en Actas de la IV Reunión de la Asociación Española de Historia Moderna (en prensa).

7. A.H.B., «Corrección, Seguridad...» Leg. 212/1.

8. A.H.B., «Correccion, Seguridad...» Leg. $212 / 3$. 
En ocasiones, las riñas afectaban a familias enteras que vivían colindantes: siete miembros de una de ellas se vieron envueltos en un fuerte altercado tras la acusación de unos a otros de «ser una cuadrilla de ladrones» lamentándose las autoridades de que no pudieran vivir en paz «como a suegros, hiernos y cuñados que son» ${ }^{9}$. Las propiedades compartidas podían asímismo ser objeto de reyerta, llegándose fácilmente a las manos por la llave de una almazara ${ }^{10}$, o la caldera de una bodega ${ }^{11}$.

Los ejemplos siguientes muestran hasta qué punto podían resultar asimismo ofensivos, los atentados contra el honor en una sociedad como la del XVIII con una concepción extrema de la honra y de la dignidad. En 1753, una mujer resultó apaleada y gravemente herida mientras estaba lavando, por calumniar a una joven soltera murmurando entre el vecindario que estaba encinta ${ }^{12}$. Solían ser los padres o los hermanos los que se tomaban la justicia por su mano arremetiendo contra los maledicentes o contra los que no cumplían la palabra de casamiento tras un contacto carnal.En sus declaraciones se reflejaba el ultraje emocional sufrido cuando expresaban que se deseaba sepultar a su familia «entre las ruhinas del descredito y el desonor» ${ }^{13}$. Igualmente grave resultaba la pretensión de una casada: la esposa de un arriero fue cortejada por un hombre que, según los testigos, «pasó en diferentes ocasiones por su casa haciendo gestos con el rostro, dando muestras de pretender alguna incontinencia como si galantease a la mujer». El marido afrentado llevó a cabo un intento de homicidio con arma blanca ${ }^{14}$.

El tiempo del ocio, en que los mozos se juntaban para divertirse, era especialmente motivo de pelea, pues los momentos de fiesta, por lo que ésta tiene de exaltación del ánimo y de transgresión del orden establecido, se prestaban a ser aprovechados para que salieran a la luz rencores y venganzas personales. Era costumbre en Biar que grupos de amigos salieran por la calle después de cenar a cantar con instrumentos musicales. Previamente se debía contar con el permiso de la alcaldía, a pesar de lo cual estos pasacalles derivaban a menudo en desórdenes públicos de importancia. Un lance ilustrativo se produjo entre dos cuadrillas que se entretenían de este modo. Los mozos de uno de los grupos que estaba estacionado en una esquina, interpelaron a los contrarios que venían calle abajo para que parasen de tocar, «porque iban rompiendo la costumbre y política de haver de parar los que vienen» y perturbaban e interrumpían su propia música. Ante el reto se enzarzaron a golpes haciéndose público al día siguiente un bando que ordenaba:

«En adelante ninguno pase tañendo vihuela aviendo otros parados en la calle bajo la pena de ser responsables de los perjuicios que resultasen» ${ }^{15}$.

En otra ocasión el alboroto lo protagonizaron una docena de jóvenes de entre 16 y 21 años que fueron encarcelados por los alguaciles al ir de noche por la Calle Ma-

9. A.H.B., «Corrección, Seguridad...» Leg. 213/2.

10. A.H.B., «Corrección, Seguridad...» Leg. $213 / 24$.

11. A.H.B., «Corrección, Seguridad...» Leg. 221/28.

12. A.H.B., «Conección, Seguridad...» Leg. 212/22.

13. Ibídem.

14. A.H.B., «Corrección, Seguridad...» Leg. 212/16.

15. A.H.B., «Corrección, Seguridad...» Leg. 212/12. 
yor «gritando y relinchando». El escándalo fue a mayores cuando de madrugada, y desde el interior de los calabozos, hicieron pedazos una de las ventanas tirando los recipientes de «excrementar» a la plaza, a resultas de lo que quedó el lugar lleno de «inmundicias y de ollas quebradas» ${ }^{16}$. Estas actuaciones hacían que los jóvenes solteros estuvieran casi siempre en el punto de mira de toda sospecha, fueran vistos con desconfianza y tenidos en escasa consideración social, por ser «gente de pocos o ningunos haveres, ligera y poco mirada» ${ }^{17}$.

Otro tipo de diversión, la práctica del juego de pelota, tradicional en muchas poblaciones valencianas, produjo diferencias entre los jugadores provocando la injuria, la riña y la bravata en donde siempre se acababa haciendo mención a la hombría ${ }^{18}$.

A la justicia le competía no sólo velar por el orden y la seguridad, sino también por el mantenimiento de la moral y las buenas costumbres. La simple injuria y el uso de términos escandalosos en la vía pública resultaban delictivos si suponían falta de respeto grave a la autoridad. Este fue el caso de una mujer que acabó ante el juzgado por el desacato de gritar al alcalde que «era un muerto de ambre y se cagava en la vara de justicia que regenta» ${ }^{19}$. Igualmente eran penalizados aquellos actos que dañaran la integridad moral de personas consideradas, como lo fueron los insultos de una vecina que desde un balcón agredió a un matrimonio de edad acusando a la mujer de ramera, y al marido, «con el otro nombre indecente que de tal como a su esposo le correspondía» ${ }^{20}$.

Por lo visto hasta ahora, cualquier pretexto por nimio que fuera, podía desembocar en desorden ya fuera una murmuración o a veces una simple sospecha, lo que explica el tono violento que adquirían las relaciones individuales. De hecho, en el fondo lo que subyacía eran antiguas querellas como así lo reconocían en numerosas ocasiones los culpables al tratar de justificar sus conductas por «hallarse desavenidos en algunas cuestiones que se movieron entre nosotros», o «estar mal allegados», lo que les llevó a actuar movidos «por el amontonamiento de ánimo» o por la cólera. En este sentido, los biarenses no fueron una excepción, pues fue normal en la época que en pueblos y ciudades se recurriera facilmente al desafío como modo directo y expeditivo para solventar diferencias ${ }^{21}$.

De la conflictividad no se vieron excluidos miembros de familias principales que ocuparon cargos políticos o administrativos en el consistorio: Destacable fue el enfrentamiento entre dos escribanos del juzgado, Gaspar Candela y Manuel Gordo. Ambos lideraron en la década de los cincuenta bandos opuestos alrededor de los que se movieron regidores, alcaldes y abogados.

En 1752, uno de los alcaldes de turno, presentó querella contra Candela por obstruccionismo en la administración de justicia, al negarse a entregar «todos los procesos, manos de cargos y otros papeles y fragmentos» pertenecientes a la escribanía del

16. A.H.B., «Corrección, Seguridad...» Leg. 212/8.

17. A.H.B., «Corrección, Seguridad...» Leg. 212/17.

18. A.H.B., «Corrección, Seguridad...» Legs. $212 / 19,213 / 15$ y $225 / 14$.

19. A.H.B., "Corrección, Seguridad...» Leg. 212/20.

20. A.H.B., «Corrección, Seguridad...» Leg. 212/28.

21. MARTÍNEZ RUIZ, E., La Seguridad puiblica... pág. 42. 
juzgado y que debían estar en poder de su sucesor en el cargo, Manuel Gordo. Candela excusó su desobediencia alegando que se le había prevenido y mandado no hacer1o. Poco le debió importar ser encarcelado por mantenerse en su negativa, sabedor como era de que su delito iba a quedar prácticamente impune, como más adelante se verá 22 .

A su vez, éste promovió pleito contra Gordo por excesos en su oficio de escribano. Para ello presentó a diez testigos, todos de humilde extracción social, que mostraron pruebas de soborno, extorsión y abusos en el cargo. En ellas se indicaba que el letrado «no tenía otra mira que estafarlos» y que era evidente «que dicho escribano haze lo que quiere en las dependencias que lleva, haziendo de juez y de escribano a la vez». En concreto se le hacía responsable de beneficiarse cobrando pagos extraordinarios «en miel, almendras, garbanzos y otras cosas comestibles» y de engañar prometiendo el favor de la justicia aprovechándose de gente pobre y necesitada. Por último, se le imputó el tener el amparo de los dos alcaldes que, por ser forastero, le fiaron 105 libras para el arriendo de la escribanía del juzgado, en perjuicio de los otros notarios naturales de la villa que no habían podido pujar en una suma que consideraron excesiva ${ }^{23}$.

Estos comportamientos corruptos, ejemplo de una violencia institucionalizada, se hacían en connivencia con los alcaldes ordinarios. Éstos no mostraban interés en remediarlos ni en aplicar la justicia con equidad, ya que también eran parte interesa$\mathrm{da}$, preocupados por enriquecerse y por ganarse el favor de los regidores de quienes dependían para volver a desempeñar su cargo en un futuro más o menos próximo ${ }^{24}$.

Como consecuencia de estos desórdenes, las oligarquías locales sufrieron venganzas personales de las que siempre responsabilizaban a la parte enfrentada acusándola de manipular a los vecinos de humilde condición. Tal es el caso del ataque del que fue objeto el antedicho Candela, a la sazón síndico procurador, golpeado públicamente por un jornalero que le llamó «lladre» y le amenazó de muerte, a resultas del cual quedó el escribano por los suelos, «descabellado» (sin peluca) y sin capa. De esta provocación inculpó a Manuel Gordo y a otros regidores como «cómplices y apandillados» ${ }^{25}$.

Sin embargo, fueron las venganzas con armas de fuego las más frecuentes a la hora de ajustar cuentas con los que controlaban el poder local. El procedimiento era siempre el mismo: aprovechar las noches especialmente lóbregas para disparar escopetazos a las ventanas de las alcobas en donde dormían las víctimas. El incidente producido el 12 de septiembre de 1752 puede resultar representativo de otros que se repitieron durante la segunda mitad de siglo. Sobre la una de la madrugada se hicieron varios disparos contra las casas de los ciudadanos Vicente Santonja y Vicente Richart y contra la de Gaspar Candela con una diferencia de «medio quarto de tiempo». Uno de los agredidos dijo quedar «atónito y lleno de espanto» y otro pensó que su casa se había hundido. Los tiros fueron acompañados de un anónimo en el que se amenazaba:

22. A.H.B., «Corrección, Seguridad..." Leg. 212/15.

23. A.H.B., «Corrección, Seguridad...» Leg. 212/17.

24. IRLES VICENTE, M.C., El régimen municipal... pp. 120-121.

25. A.H.B., «Correción, Seguridad...» Leg. 212/23. 
«los pobres no pueden pagar las cargas y ustedes compran molinos y olivares... y les advierto por el amor de Dios que no lo tomen a chanza porque cuando lo quieran remediar no van a poder... ya sabemos que ustedes son los amos y el mejor remedio son las balas». En este caso se trató de un episodio en torno a la fiscalidad, en el que se receló de algunos regidores como «malcontentos y quexosos» en el reparto del equivalente por criticar públicamente la injusta distribución del impuesto entre los contribuyentes de la población. Como principal instigador se acusó a Manuel Gordo «por quererse manifestar en protector de pobres» ${ }^{26}$.

Los mismos problemas generadores de disturbios -división de facciones, práctica de parcialidades- han sido detectados por estos años para otras poblaciones valencianas con alcaldes ordinarios como Cullera, Callosa de Segura y Villajoyosa ${ }^{27}$.

El uso y tenencia de armas, fue objeto de estrictas prohibiciones en tierras valencianas durante el XVIII, y de su incumplimiento se derivaron severas penas. Sin embargo ello no impidió su circulación clandestina debido, en gran parte, a las actividades corruptas de aquellos que cercanos a las altas instancias de la administración, tuvieron ocasión de traficar con ellas ${ }^{28}$. Miguel Ferriz, que regentaba la alcaldía en 1756 , se quejaba de esta práctica «que muy continuadamente se experimenta en esta villa de Biar de hir de noche por las calles haciendo madrinas y disparando escopetazos a las puertas y ventanas» ${ }^{29}$.

Las penas impuestas por la justicia, encaminadas al escarmiento del culpable y a la disuasión del potencial agresor, demuestran que la actuación de los jueces estuvo caracterizada con frecuencia por la lentitud y el trato discriminatorio, pues el castigo no se aplicó con el mismo rasero a los personajes influyentes y al común de los vecinos.

Éstos últimos, protagonistas de numerosas riñas eran encarcelados de inmediato, sin distinción entre inocente y culpables y sus escasos bienes embargados. La investigación de los hechos solía ser un proceso largo con declaración de numerosos testigos a favor o en contra, careos e informes pormenorizados de los cirujanos sobre las heridas causadas, en el que las autoridades no mostraban prisa por resolver el caso.

Era por tanto, normal que permanecieran en prisión preventiva un mes o más hasta que se dictaba la resolución final, lo que resultaba particularmente desproporcionado en el caso de faltas menores. Los perjuicios ocasionados al reo no eran pocos, de modo que la petición respetuosa de agilización de la causa y de libertad, se convertía casi en una fórmula, en donde se alegaba lo avanzado de la edad o la calamidad que suponía estar preso para la manutención de la familia y el cuidado de los bienes.

Estos casos contrastan con los de otros culpados que tuvieron trato de favor como el ya citado escribano Candela que gozó de un cómodo régimen carcelario duran-

26. A.H.B., «Correción, Seguridad...» Leg. 212/11. Los puntos suspensivos del anónimo obedecen a su ilegibilidad.

27. IRLES VICENTE, M. C., «Nuevas varas valencianas...» (en prensa).

28. GIMÉNEZ LÓPEZ, E., «Un aspecto de la normalización política en la Valencia borbónica. El cambio de la legislación sobre el uso de armas» en Anales Valentinos, n 31, 1990, pp. 126-127.

29. A.H.B., «Corrección, Seguridad...» Leg. 213/10. El término «madrina» hace referencia a los atentados con armas de fuego. 
te sólo cinco días, saliendo a cenar y a dormir a su casa a voluntad y sin que mediara ninguna orden en este sentido de la autoridad judicial ${ }^{30}$.

La circunstancia del encarcelamiento prolongado propiciaba el reconocimiento de la culpabilidad así como el deseo de reconciliación, sobre todo, en los sumarios de cargos menores, que se daban por concluidos con una multa y el apercibimiento de los alcaldes de contener la animosidad en sucesivas ocasiones. En estos casos, a las mujeres se las solía condenar a arresto domiciliario «en atención a la calidad de la causa y del sexo del reo» ${ }^{31}$. Los mozos alborotadores menores de 25 años podían elegir a su propio tutor o defensor, función que acababa siempre desempeñando el alguacil, quizá por la costumbre o por el respeto y la confianza que ejerciera entre los jóvenes totalmente ignorantes de los procedimientos legales.

En los autos del juzgado no quedó registrado ningún caso de asesinato, pero los delitos con intenciones homicidas en los que el daño físico era particularmente grave pasaban a seguirse en la Real Audiencia de Valencia, en donde la condena dictada podía ser el servicio forzoso en el ejército durante varios años.

Especial celo observaron las autoridades acerca del uso y tenencia de armas. En caso de que el delincuente huyera amparado por la nocturnidad y la vestimenta de la época, que era lo más común, se realizaba una exhaustiva indagación en el entorno del sospechoso en el que los familiares podían llegar a ser encarcelados por encubridores. Si alguien era sorprendido o denunciado por portar o esconder un arma, la sanción era especialmente dura: un vecino soportó un año de destierro por salir con una carabina a buscar al que había realizado estupro con su hija ${ }^{32}$. Por la ocultación de un arma similar se vieron complicados varios hermanos y el cerrajero que la reparó, como cómplice por no denunciar su existencia. Para todos se pidieron «las mayores y mas graves penas en que respectivamente hubieran incurrido» ${ }^{33}$.

Los palos y bastones fueron los objetos contundentes más utilizados por su fácil accesibilidad y sobre los que también se dictaron normativas. Una vez aprehendidos se sometían al reconocimiento de los maestros carpinteros que emitían dictámenes como el siguiente: «dicen no ser de los prohibidos pues sobre no tener porra son delgados y no tienen la gordaria que previene la orden antedicha» ${ }^{34}$

La violencia cotidiana tuvo en Biar un ritmo ascendente durante la segunda mitad de siglo, de modo que en la década de los ochenta las tensiones se agudizaron y menudearon los apaleamientos y la presencia nocturna de hombres acuadrillados con cayados escondidos bajo los ropajes. Todo ello en contra de la orden dictada en 1780 por la Sala del Crimen de la Audiencia de estar más de tres reunidos en la calle después de tañer la campana de queda ${ }^{35}$.

En este aumento de la conflictividad, tuvo mucho que ver la pervivencia de un rudimentario sistema judicial que contó con muchas deficiencias. Entre ellas, el esca-

\footnotetext{
30. A.H.B., «Corrección, Seguridad...» Leg. 212/15.

31. A.H.B., «Corrección, Seguridad...» Leg. 212/20.

32. A.H.B., «Corrección, Seguridad...» Leg. $213 / 8$.

33. A.H.B., «Corrección, Seguridad...» Leg. 213/10.

34. A.H.B., «Corrección, Seguridad...» Leg. 222/11.

35. A.H.B., «Corrección, Seguridad...» Legs. 222/1, 222/3, 222/4 y 222/11.
} 
so desarrollo institucional en materia de orden público que habilitaba a los naturales para regir los tribunales, con las arbitrariedades que de ello se derivaban; la insuficiencia de medios para perseguir la ilegalidad se hace por igual evidente, pues se suplía en ocasiones recurriendo al propio vecindario y promoviendo las delaciones, lo que contribuía a alimentar los odios y las rencillas. De este modo se resolvían los casos de deserción: aquel que descubriera y prendiera a un prófugo podía liberar del servicio de armas a su propio hijo o al pariente que eligiera. La recompensa era lo suficientemente tentadora como para que no se regatearan medios ni tiempo en el empeño, aunque el delator debiera costear «todos los gastos de conducciones, regresos y matenimientos» del evadido ${ }^{36}$.

La solución a los reiterados problemas de orden público, vino dada por el nombramiento de un alcalde mayor en 1791, dentro de un proceso escalonado que se dio también para otras poblaciones valencianas a fines de siglo, de nombrar nuevas varas de justicia. El alcalde mayor, al no ser natural del lugar donde iba a ejercer su jurisdicción, mantenía mejor su independencia evitando presiones de familiares y amigos.

La petición fue hecha en 1787 por el síndico personero para acabar con las continuas disputas entre facciones, aunque diferentes contratiempos retrasaron la adopción de dicha medida. La dotación de alcalde mayor tuvo un efecto beneficioso ya que supuso la pacificación de la villa ${ }^{37}$. Este hecho se observa en el notable descenso de los conflictos según la documentación judicial del archivo de Biar, que coincide con la valoración que hizo la Audiencia a la muerte del primer alcalde mayor, acaecida antes de finalizar el preceptivo sexenio. En ella se destacaba que habían cesado las discordias que motivaron su establecimiento. Los obstáculos para que el rey refrendara por otros seis años la continuidad del cargo, vinieron dados por la reticencia de algunas facciones de vecinos y por las dificultades económicas del municipio para satisfacer el salario del titular. Ambos fueron superados por los informes favorables de la Audiendia y de los alcaldes mayores de otras poblaciones, que confirmaron las ventajas que había experimentado Biar en orden a la tranquilidad de sus moradores. Finalmente, acabó primando la recta administración de justicia por encima del desahogo económico del municipio, y la vara biarense fue confirmada de nuevo ${ }^{38}$.

El apaciguamiento de la villa tras este refuerzo institucional, corrobora que las alteraciones del orden público en Biar fueron el resultado de acciones individuales, o de pequeños grupos movidos por la revancha o por la ambición personal dentro del reducido espacio de la villa, y que su asiduidad en el ámbito de lo cotidiano, son la expresión de hábitos y actitudes de tipo estructural, que aún hoy de modo excepcional reaparecen.

36. A.H.B., «Corrección, Seguridad...» Leg. 215/15.

37. IRLES VICENTE, M. C., «Nuevas varas valencianas...» (en prensa).

38. Ibídem. 